Review

\title{
Synaptic Plasticity-Regulated Gene Expression: a Key Event in the Long-Lasting Changes of Neuronal Function
}

\author{
Akiko TABUCHI \\ Graduate School of Medicine and Pharmaceutical Sciences, University of Toyama; \\ 2630 Sugitani, Toyama, Toyama 930-0194, Japan. \\ Received December 10, 2007
}

\begin{abstract}
"Neuronal activity"-dependent transcriptional activation is required for the long-lasting, functional changes that are involved in memory consolidation or drug addiction. Elucidation of the molecular mechanisms underlying the neuronal activity-dependent transcription of synaptic plasticity-related genes has helped towards understanding neuronal function and disorders as well in identifying new target molecules for drug design. In this study, we focused on neurotrophin and neuropeptide, which both have the ability to modulate neuronal survival and function. We also examined the molecular mechanisms by which underlying neurotrophin genes are regulated by neuronal activity. Brain-derived neurotrophic factor (BDNF) is a neurotrophin family member that has important roles in neuronal survival and plasticity as well as in psychiatric disorders. Transcriptional activation of the BDNF gene is commonly regulated by a key transcription factor, cAMP response element-binding protein (CREB), and this at least in part contributes to neuronal activity-dependent neuronal survival. Among at least four distinct promoters of the BDNF gene, promoters I and III are differentially activated by $\mathrm{Ca}^{2+}$ signals via NMDA receptors and L-type voltage-dependent $\mathrm{Ca}^{2+}$ channels. Especially, BDNF gene promoter I activation requires the cooperative binding of and upstream stimulatory factor (USF) and CREB to a CRE/USF binding site. By contrast, NT-3 gene transcription is regulated by Sp3/4. An important future direction will be to elucidate how long-lasting changes in neuronal plasticity are "epigenetically" and "structurally" controlled. Our studies on the relationships between long-lasting neuronal responses and gene expressions should help guide research into novel drugs for neuronal or psychiatric disorders.
\end{abstract}

Key words brain-derived neurotrophic factor; synaptic plasticity; gene expression; neuronal activity; neurotrophin-3; epigenetics

\section{INTRODUCTION}

Synaptic transmission plays an essential role in brain function. This specialized form of cellular communication acts not only as a signaling mechanism between neurons but also drives functional changes in neurons. At synapses, neurotransmitters are released from presynaptic terminals and act on receptors to activate a number of biochemical signaling cascades including cAMP, protein kinase A and mitogen-activated protein kinases (MAPKs), in postsynaptic spines of neurons. One of the most important processes is elevation of intracellular $\mathrm{Ca}^{2+}$ : high frequency extra-cellular stimuli yields a highly efficient form of synaptic transmission that results in a long-lasting or a rapid influx of $\mathrm{Ca}^{2+}$. Although $\mathrm{Ca}^{2+}$ signals activate $\mathrm{Ca}^{2+} /$ calmodulin-dependent protein kinase (CaMKs) and mitogen-activated protein kinases

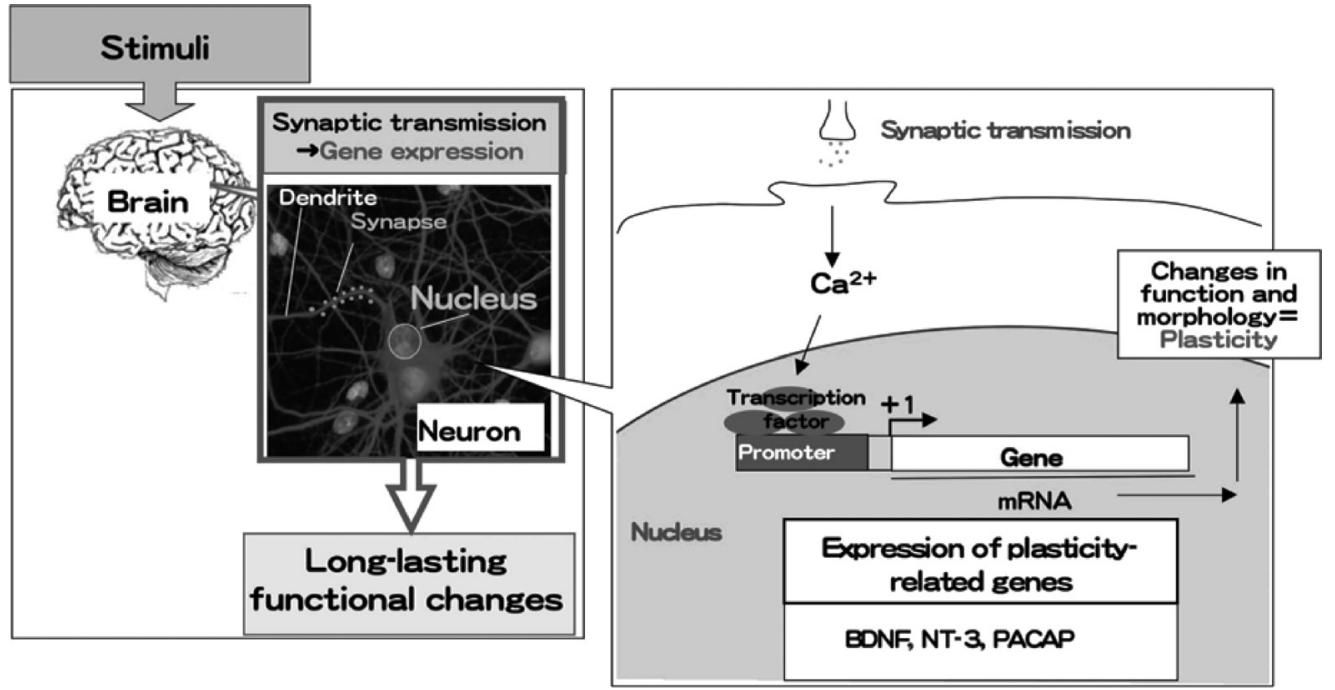

Fig. 1. Environmental Stimuli Evoke High Frequency Synaptic Transmission and Synaptic Plasticity-Regulated Gene Expression

High frequency extracellular stimuli cause adaptive changes in the structure and function of neurons, leading to long-lasting functional changes in the brain. During this process, neurotransmitter receptor activation triggers a number of signal transductions pathways, of which the $\mathrm{Ca}^{2+}$ signal is thought to be one of the most important signals carried to the nucleus because it affects expression of synaptic plasticity-regulated genes in neurons. In this review, we focused on the synaptic plasticity-regulated genes BDNF, NT-3 and PACAP genes to clarify their transcriptional and post-transcriptional mechanisms. 
(MAPKs) cascades, $\mathrm{Ca}^{2+}$ signals are finally transduced into the nucleus to regulate a variety of transcription factors and hence, gene expression. Activity-dependent gene expression is thought to be involved in the long-lasting changes in neuronal function that occur with drug addiction. Moreover, the processes of learning and memory are thought to be driven by synaptic plasticity, which is a remarkable feature of the brain (Fig. 1). ${ }^{1)}$ Therefore, it is important to know how the $\mathrm{Ca}^{2+}$ signal is transduced to the nucleus and which genes are regulated by these signals in neurons. Here I review our recent studies on the transcriptional regulation of the synaptic plasticity-regulated genes, brain-derived neurotrophic factor (BDNF), neurotrophin-3 (NT-3) and pituitary adenylate cyclase activating polypeptide (PACAP), their physiological role in neurons and discuss future directions.

\section{TRANSCRIPTION OF THE BDNF GENE}

Brain-derived neurotrophic factor (BDNF), a member of the neurotrophin family, plays a critical role in neuronal survival, differentiation and synaptic plasticity. ${ }^{2)}$ BDNF is predominantly expressed in the central nervous system, and its mRNA expression is up-regulated by neuronal activity that is accompanied by $\mathrm{Ca}^{2+}$ influx into the postsynaptic spines of neurons. ${ }^{3,4)}$

The BDNF gene consists of four $5^{\prime}$-non-coding exons (exons I, II III, IV) and a 3 '-exon, exon V, that encodes the preproBDNF mRNA, giving rise to a total of eight transcripts (exons I-V, II-V, III-V and IV-V) (Fig. 2). ${ }^{5}$ Four promoters have been mapped upstream of exons I, II, III and IV, and these promoters are differentially activated by kainic acid-induced seizure in distinct regions of the rat brain. ${ }^{5)}$ The structure of the BDNF gene is complicated and the use of alternative promoters suggests that diversity and flexibility of
BDNF gene expression is required for the fine-tuning of BDNF function. Therefore, it is very important to know how BDNF gene promoters are regulated and to understand the cellular mechanisms that control BDNF expression in neurons.

We performed reverse-transcription polymerase chain reaction (PCR) analysis to determine which of the BDNF gene promoters are activated by $\mathrm{KCl}$-induced membrane depolarization. Transcripts containing exons I, II and III, except for exon IV, were up-regulated in rat cortical neurons (Fig. 4). ${ }^{6}$ In particular, transcripts pertaining to exons I-V and III-V were predominantly increased, therefore, we decided to analyze BDNF gene promoters I and III. In many cases, promoter analyses were performed in cell lines and not in primary cultured neurons because of the low efficiency of transfection. However, we designed the assay system for measuring the activity of calcium responsive promoters in rat cortical neurons.

We used a dual-luciferase reporter assay with two different kinds of luciferase reporter and internal control vectors derived from the firefly and Renilla. Next, we selected an internal control promoter (for example, thymine kinase (TK) or elongation factor $1 \alpha(\mathrm{EF} 1 \alpha)$ gene promoter) that is not responsible for calcium signals, and inserted it upstream of the Renilla gene. Finally, we used the calcium phosphate-precipitation method to transfect DNA into primary cultured cortical or hippocampal neurons. Using these methods we successfully measured calcium-responsive BDNF gene promoter activity in primary cultures of neurons (Fig. 5). ${ }^{7}$ Membranedepolarization caused by high concentrations of $\mathrm{K}^{+}(25$ or $50 \mathrm{~mm} \mathrm{KCl}$ ) was effective in the induction of BDNF mRNA expression and activation of promoters I and III (Fig. 5). Under these conditions, extracellular $\mathrm{Ca}^{2+}$ influx occurs via $N$-methyl-D-aspartate (NMDA) receptors and L-type voltage-

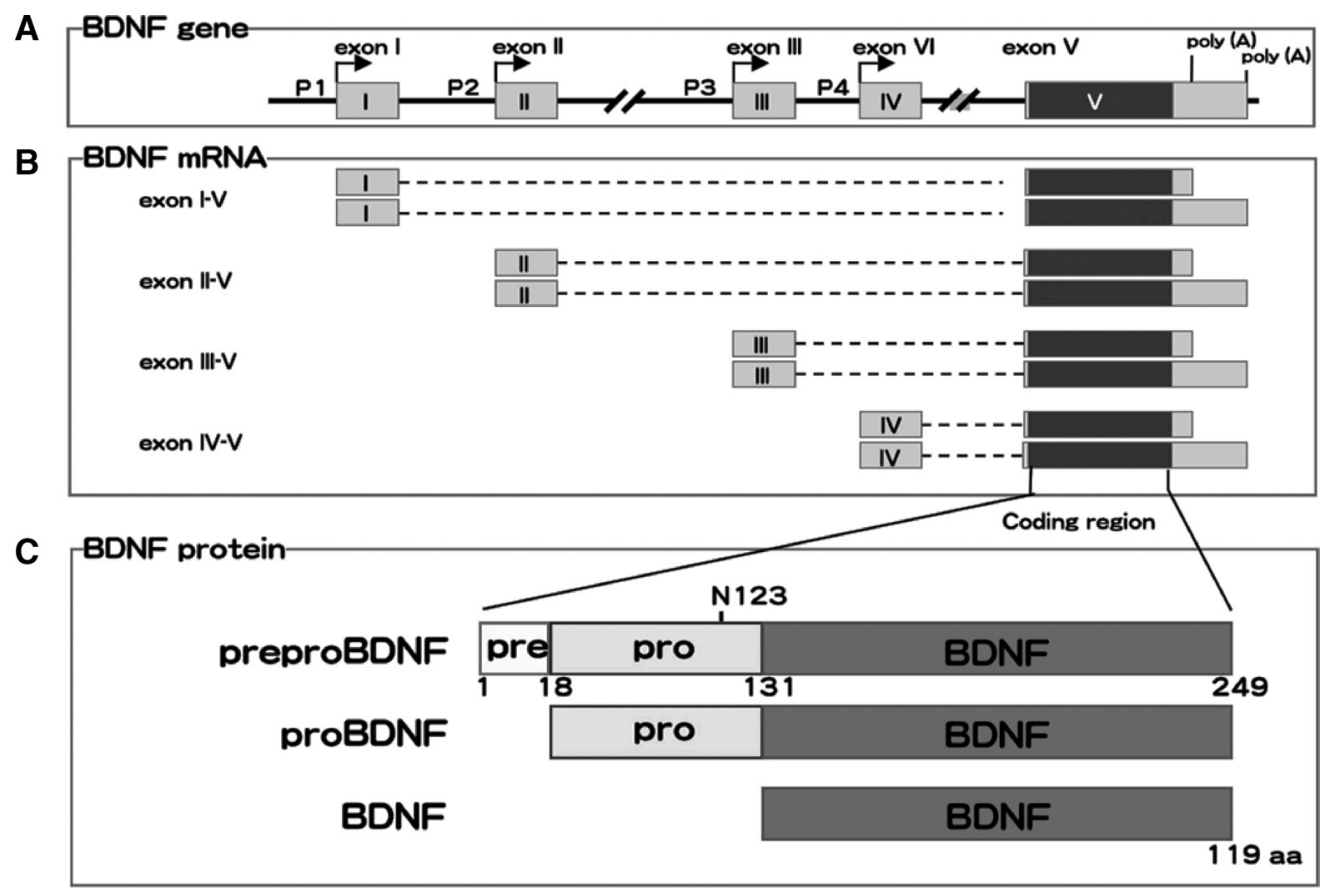

Fig. 2. Structure of the Rat BDNF Gene, Transcript and Protein

(A) Diagram of the rat BDNF gene structure as described by Timmusk et al. ${ }^{5)} \mathrm{P} 1, \mathrm{P} 2, \mathrm{P} 3$ and P4 indicate promoters I, II, III and IV, respectively. Open boxes represent 5 ' -alternative non-coding exons. The solid box indicates the coding exon. The presence of alternative exons and two distinct polyadenylation signals give rise to eight transcripts as shown in (B). (C) Only exon V codes for the preproBDNF protein. Proteolytic cleavage of the preproBDNF protein leads to mature BDNF production. 


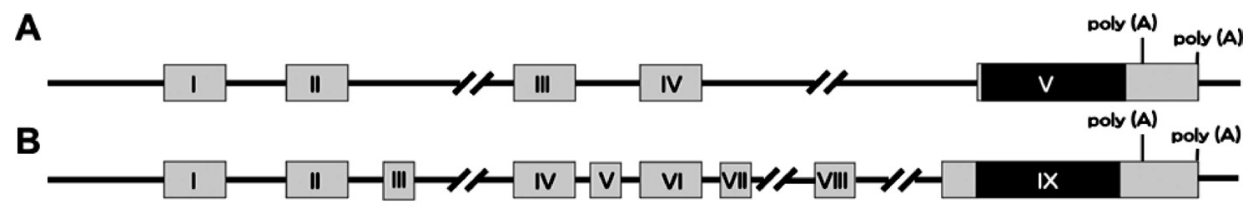

C

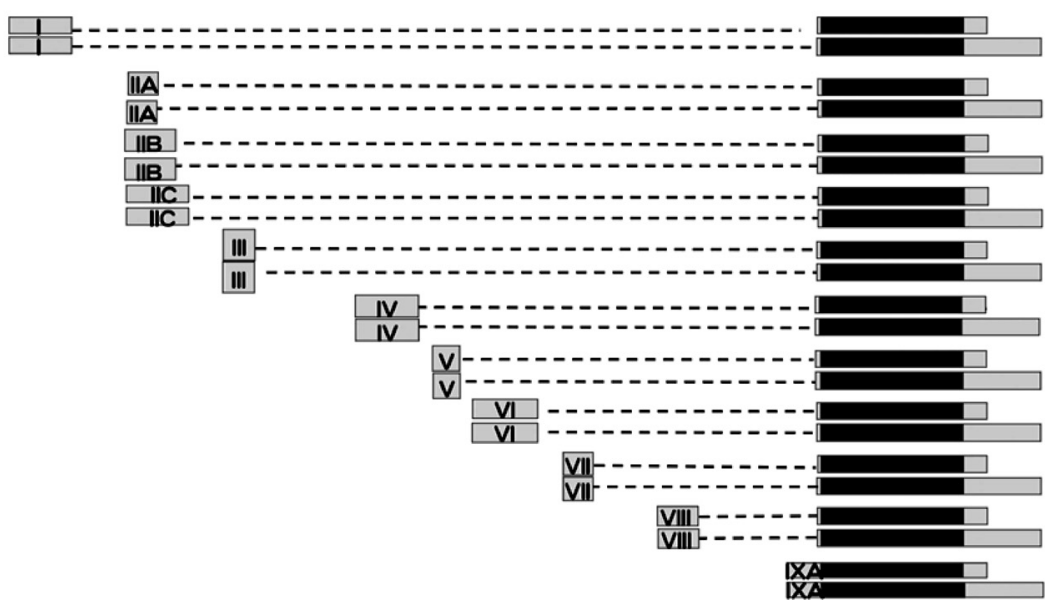

Fig. 3. Comparison of the 'Old' BDNF Gene Structure with the Recently Revised Structure

(A) Rat BDNF gene structure as described in Fig. 2A. (B) The new arrangement of mouse and rat BDNF genes as described by Aid et al. ${ }^{25)}$ The authors analyzed DNA and mRNA sequence data using bioinformatics, 5 RACE and RT-PCR. The BDNF gene contains 5 '-alternative non-coding exons and one protein coding exon. The three alternative splice donor sites within exon II, the alternative non-coding exons and two polyadenylation signals eventually give rise to twenty-two transcript species as shown in (C).
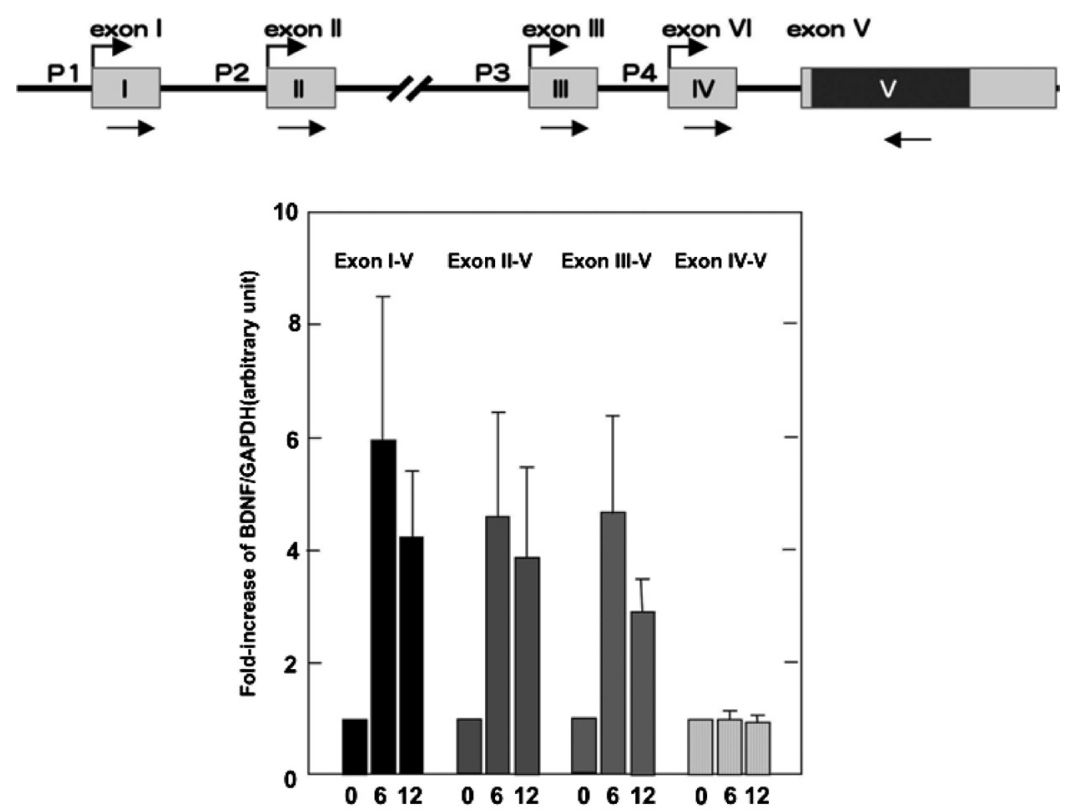

Time after KCl-stimulation (h)

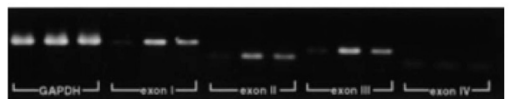

Fig. 4. Membrane Depolarization-Induced BDNF mRNA Transcripts in Rat Cortical Neurons

Arrows indicate the sense primers that correspond to each of the $5^{\prime}$-non-coding exons and an antisense primer that corresponds to the $3^{\prime}$-coding exon. Rat cortical neurons $(5 \mathrm{~d}$ in vitro) were stimulated with $25 \mathrm{~mm} \mathrm{KCl}$, and total RNA was isolated at the time indicated $(0,6,12 \mathrm{~h})$ and subjected to RT-PCR. The relative intensities of the amplified DNA fragments containing each exon were analyzed with an Image scanner and plotted. Cited from Tabuchi et al. ${ }^{6}$

dependent $\mathrm{Ca}^{2+}$ channels (L-VDCC), since ${ }^{45} \mathrm{Ca}^{2+}$ influx was completely blocked by simultaneous administration of two $\mathrm{Ca}^{2+}$ channel antagonists, nicardipine, an antagonist of LVDCC, and DL-amino-5-phosphonovalerate (APV), an antagonist of NMDA receptors (Fig. 6A) ${ }^{8}{ }^{8}$ Both BDNF gene pro- moters I and III were up-regulated by activation of these two $\mathrm{Ca}^{2+}$ entry sites (Figs. 6B, C). However, the two promoters responded differently to the two $\mathrm{Ca}^{2+}$ channel antagonists (Figs. 6B, C). BDNF promoter I activation was repressed by nicardipine, but not by APV, whereas promoter III activity 


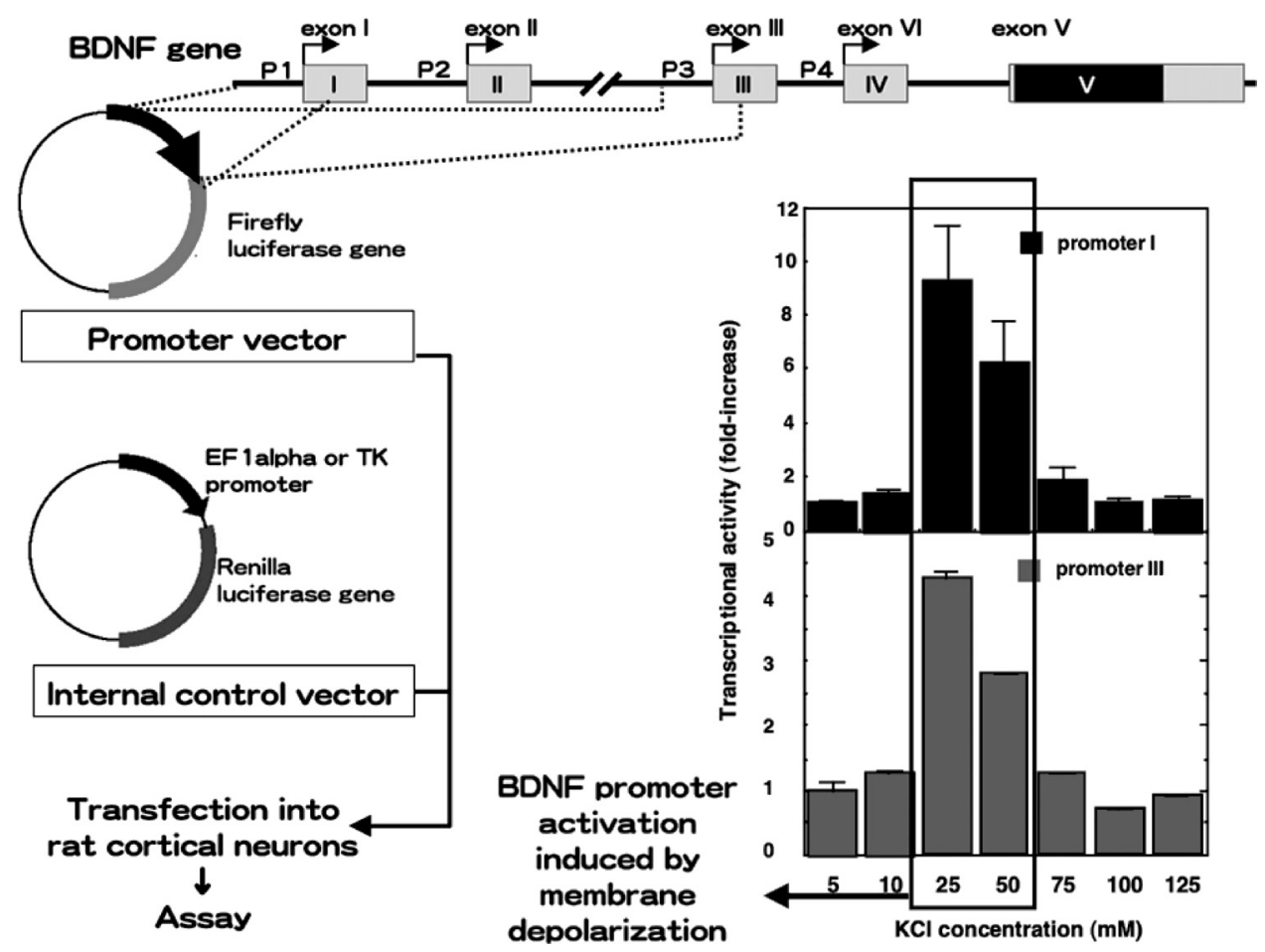

Fig. 5. Dual-Luciferase Reporter Assay for Measuring $\mathrm{Ca}^{2+}$-Responsive Promoter Activity and Activation of BDNF Gene Promoters I and III by Membrane Depolarization

The promoter vector (pGL3-BDNFpI or pGL3-BDNFpIII) was constructed by linking BDNF gene promoters I or III to the firefly luciferase gene. The internal control vector (pRL-EF $1 \alpha$ or phRL-TK), which does not respond to $\mathrm{Ca}^{2+}$ signals, was selected. In this study, elongation factor $1 \alpha(\mathrm{EF} 1 \alpha)$ or the thymidine kinase (TK) gene promoter was selected. Cortical neurons were transfected with $8 \mu \mathrm{g} / 60 \mathrm{~mm}$ dish of pGL3-BDNFpI or pGL3-BDNFpIII plus pRL-EF1 $\alpha$ by the DNA-calcium phosphate precipitation method and incubated for $40 \mathrm{~h}$. Cellular extracts were prepared for the luciferase assay $12 \mathrm{~h}$ after stimulation with KCl. 25 or $50 \mathrm{~mm} \mathrm{KCl} \mathrm{effectively} \mathrm{activated} \mathrm{BDNF} \mathrm{promoters} \mathrm{I} \mathrm{and} \mathrm{III.} \mathrm{Cited}$ from Tabuchi et al. ${ }^{8)}$
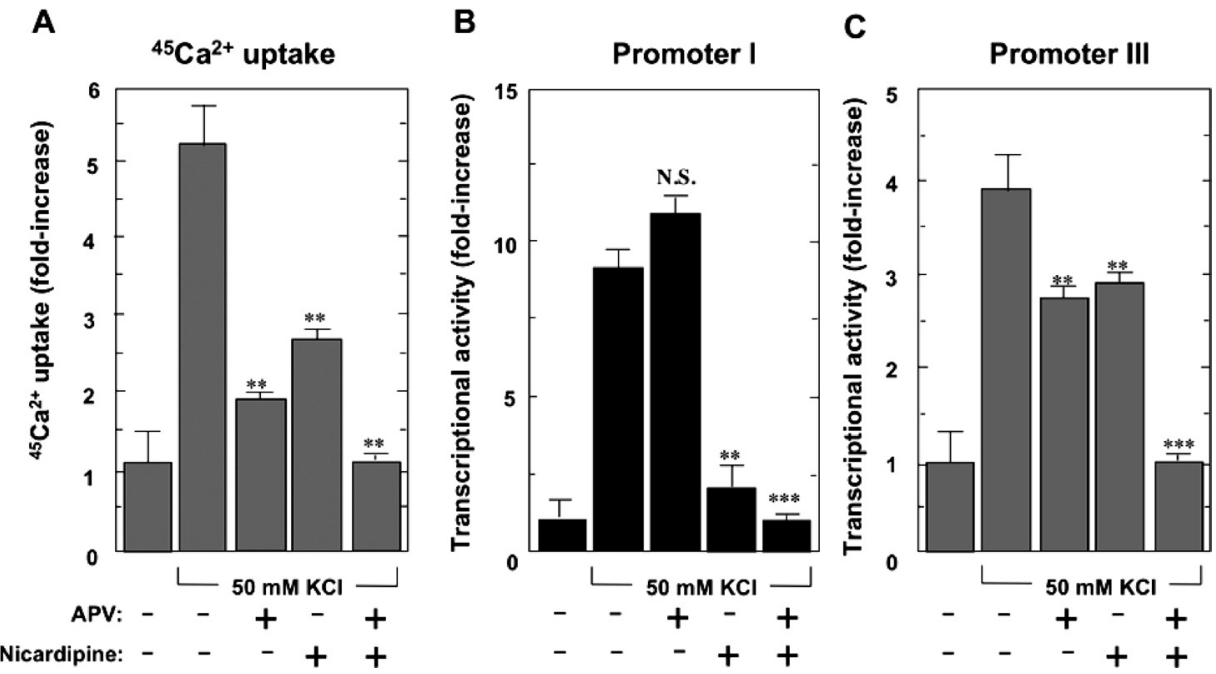

Fig. 6. Effect of $\mathrm{Ca}^{2+}$ Channel Antagonists on the Activation of BDNF Gene Promoters I and III Induced by Membrane Depolarization

(A) ${ }^{45} \mathrm{Ca}^{2+}$ uptake after treatment with $\mathrm{Ca}^{2+}$ channel antagonists, $200 \mu \mathrm{M}$ APV and/or $5 \mu \mathrm{m}$ nicardipine. APV or nicardipine alone only partially inhibited $\mathrm{Ca}^{2+}$ uptake. However, simultaneous addition of APV and nicardipine resulted in complete blockade of $\mathrm{Ca}^{2+}$ uptake, indicating that $50 \mathrm{mM} \mathrm{KCl-induced} \mathrm{Ca}^{2+}$ uptake depends upon the activation of two $\mathrm{Ca}^{2+}$ channels, NMDA receptors and L-VDCC. (B) and (C) show that activity of BDNF gene promoters I and III is affected by $\mathrm{Ca}^{2+}$ channel antagonists, respectively. $p<0.01$ $(* *), p<0.001(* * *)$, and $p$ is not significant (N.S.) with respect to the control without antagonists. Cited from Tabuchi et al. ${ }^{8)}$

was partially blocked by nicardipine or APV alone, but completely blocked by their simultaneous administration. These findings indicate that activation of BDNF promoter I is sensitive to $\mathrm{Ca}^{2+}$ entry via $\mathrm{L}-\mathrm{VDCC}$, whereas that of promoter III requires $\mathrm{Ca}^{2+}$ entry via both $\mathrm{L}-\mathrm{VDCC}$ and NMDA receptors. Differential usage of BDNF gene promoters in cortical neurons could be involved in controlling the multiple functions of BDNF in the mammalian nervous system.

Next, we tried to identify $\mathrm{Ca}^{2+}$-responsive DNA elements of BDNF promoter I and the transcription factors that bind to these responsive elements. Analysis of reporter activation with several mutants of BDNF promoter I revealed a requirement for two promoter regions in the transcriptional response to $\mathrm{KCl}$-induced membrane depolarization (Fig. 7). ${ }^{6}$ Specifi- 


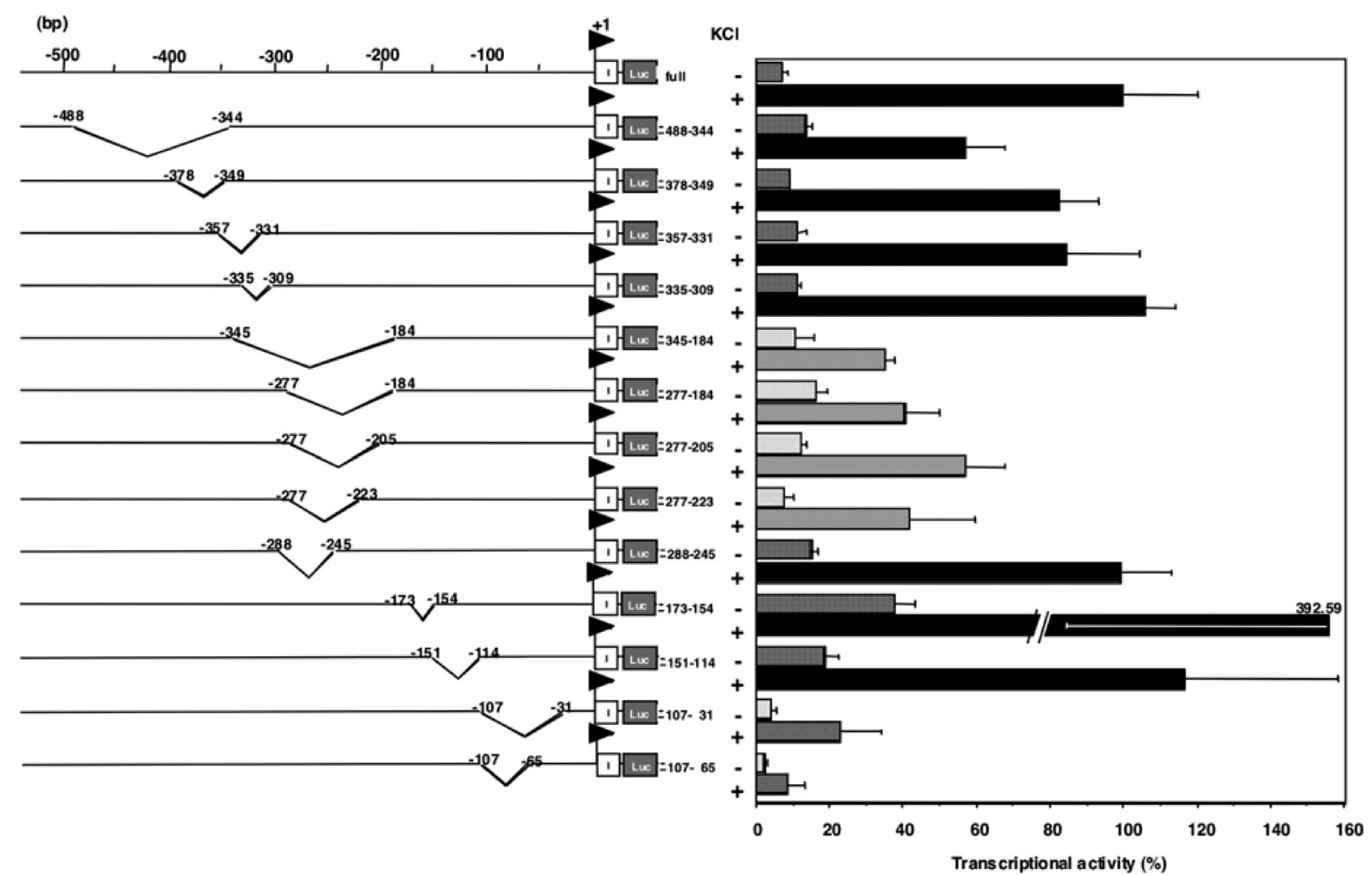

Fig. 7. Calcium-Responsive Elements Located in the Distal and Proximal Regions of BDNF Gene Promoter I

Reporter vectors carrying various constructs of the BDNF gene promoter I were transfected into rat cortical neurons. The use of plasmid vectors pBDNF pI ( $\Delta 345-184)$, $-(\Delta 377-184),-(\Delta 377-205)$ and $-(\Delta 377-223)$ resulted in a decrease in $\mathrm{Ca}^{2+}$ responsiveness. Highly $\mathrm{Ca}^{2+}$-responsive elements were suggested to be localized to the proximal regions $(-107--31)$ or $(-107--65)$. Cited from Tabuchi et al. ${ }^{6}$

cally, the proximal region from -107 to -65 was extremely effective in activation of BDNF promoter I. Thus, we focused on this region and investigated which DNA sequences within this region contribute to the activation. We found a cAMP response element (CRE) and upstream stimulatory factor (USF)-binding element (UBE) in this region that overlapped with each other. We found that CRE-binding protein (CREB) and USF bind to and activate BDNF promoter $\mathrm{I}$ at the CRE/UBE site (Fig. 8).

Another $\mathrm{Ca}^{2+}$-responsive promoter, BDNF promoter III, has been characterized. BDNF promoter III contains three $\mathrm{Ca}^{2+}$-responsive elements (CaREs), CaRE1, CaRE2 and CaRE3. In addition to CREB, which specifically binds to CaRE3, USF binds to CaRE2 and thereby contributes to BDNF promoter III activation. 9-11) Furthermore, CaRF, a calcium response factor, binds to CaRE1 and activates transcription of BDNF exon III. ${ }^{12)}$ These findings suggest that CREB and other transcription factors cooperatively bind BDNF promoters I and III and that this could be a general mechanism for determination the specificity of gene expression in response to $\mathrm{Ca}^{2+}$ signals (Fig. 8).

As described above, we and other groups have reported that positive regulators control BDNF gene transcription. However, there are also a number of transcriptional repressors of BDNF expression. Neural restrictive silencer element/repressor element-1 (NRSE/RE-1) has been identified as a negative acting DNA element that inhibits the expression of neuronal genes in non-neuronal cell types and in neuronal subtypes. ${ }^{13,14)}$ NRSE/RE-1 was found between exons I and II, in proximity to BDNF promoter II and this repressor had

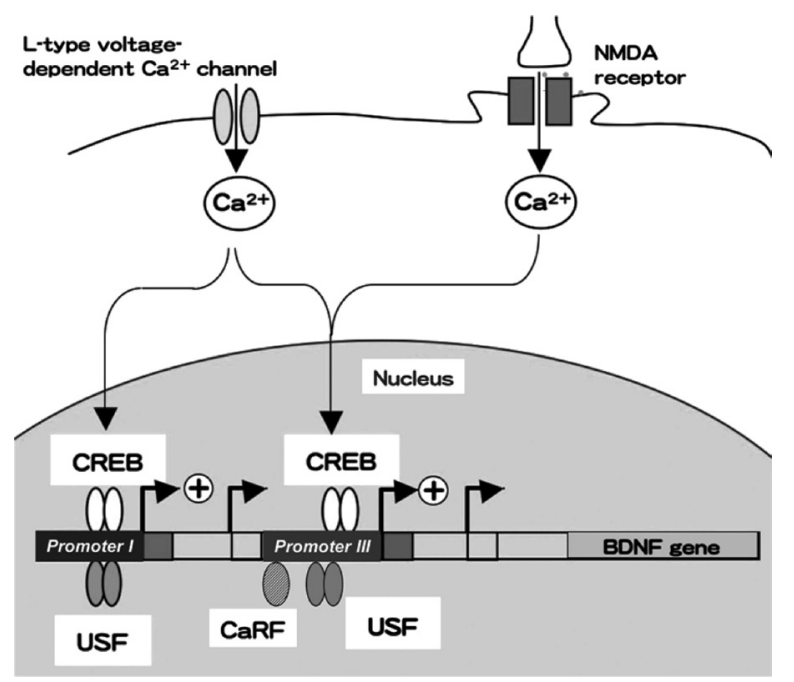

Fig. 8. Summary of BDNF Gene Transcription Mechanisms by $\mathrm{Ca}^{2+} \mathrm{Sig}-$ nals

BDNF gene promoter I responds only to $\mathrm{Ca}^{2+}$ entry via L-VDCC. Transcription factor CREB and USF bind to an overlapping sequence at the CRE/UBE site and promote transcription of exon I-containing BDNF transcripts. Promoter III is able to respond to $\mathrm{Ca}^{2+}$ entry via L-VDCC and NMDA receptors. In addition to CREB and USF, a novel calcium responsive transcription factor, $\mathrm{CaRF}$, coordinately promotes BDNF promoter III activity.

been shown to be functional in the brain. ${ }^{15)}$ These findings prompted us to study the silencing effect of NRSE/RE-1 on transcription of chimeric promoters in which NRSE is linked to upstream of BDNF promoter I and c-fos promoter. These chimeric promoters had a marked repressive effect in pri- 
mary glial cells but not in primary cortical neurons. ${ }^{16)}$

We wanted to identify the transcription factors that bind to NRSE/RE-1 by using the chimeric promoters of the BDNF or c-fos gene. Over-expression of the zinc finger transcription factor RE-1-silencing transcription factor (REST)/neuron-restrictive silencer factor (NRSF) ${ }^{17,18)}$ resulted in repression of $\mathrm{BDNF}$ promoter I activity during $\mathrm{KCl}$-stimulation. On the other hand, co-expression of REST4, which is a C-terminally truncated, neuronal-specific form of REST/NRSF, completely inhibited the silencing of BDNF promoter I by REST/NRSF. ${ }^{19)}$ Furthermore, Millecamps et al. reported that NRSE/RE-1 was used to target gene expression of vectors specifically to neuronal cells. ${ }^{20}$ ) These findings indicate that linkage of NRSE to any promoter allows neuronal-specific expression of a gene of interest and avoids ectopic expression in non-neuronal cells. In other words, this NRSE strategy may be useful for gene therapy in the treatment of neurological disorders.

Another suppressor is Methyl-CpG-binding protein 2 (MeCP2), a member of the methyl-CpG-binding domain (MBD) family, which functions as a repressor that mediates silencing through binding to methylated $\mathrm{CpG}$ islands. ${ }^{21)}$ MeCP2 mutations are a cause of Rett syndrome (RTT), an Xlinked neurological disorder that leads to mental retardation in females. ${ }^{22)}$ Recently, MeCP2 has been reported as a regulator of BDNF gene transcription. Phosphorylation of $\mathrm{MeCP} 2$ at serine 421 is induced selectively in the brain and releases $\mathrm{MeCP} 2$ from BDNF promoter III, thereby activating transcription, dendritic arborization and maturation of dendritic spine morphology. ${ }^{23,24)}$ Taken together, BDNF gene transcription plays an important role not only in neuronal function, but also in neurological disorders.

Notably, recent research into the BDNF gene has resulted in revision of the gene organization. Rat and mouse BDNF gene structures and expression are more complicated than initially reported. ${ }^{25)}$ Both mouse and rat BDNF genes consist of eight $5^{\prime}$ non-coding exons (exon I, II, III, IV, V, VI, VII and VIII) and a common exon IX encoding a preproBDNF protein. It is thought that this combination of exons may give rise to twenty-two BDNF transcripts (Fig. 3) driven by nine promoters, which were mapped upstream of the nine $5^{\prime}$ exons. In this review, however, we refer to the previous structure of the rat BDNF gene, which consists of four 5' exons, a common exon $\mathrm{V}$ and four promoters (Fig. 2). Therefore, exons I and III correspond to exons I and IV in the revised gene structure, respectively (Figs. 2, 3). The human BDNF gene structure is more complex than that of the rodent one: it has eleven exons and nine functional promoters. Interestingly, in the human gene locus non-coding antisense RNAs are transcribed, suggesting that expression of BDNF gene in humans is incredibly complex. ${ }^{26}$ )

\section{TRANSCRIPTION OF THE NEUROTROPHIN-3 GENE}

Neurotrophin-3 is also a member of the neurotrophin family, which includes BDNF and neurotropin-4/5. ${ }^{27-29)}$ Despite several reports on the transcriptional regulation of the BDNF gene and the importance of NT-3 function, the molecular mechanisms that control NT-3 gene transcription are not fully understood. Therefore, we analyzed the responsiveness of NT-3 gene promoters to various stimuli. The NT-3 gene

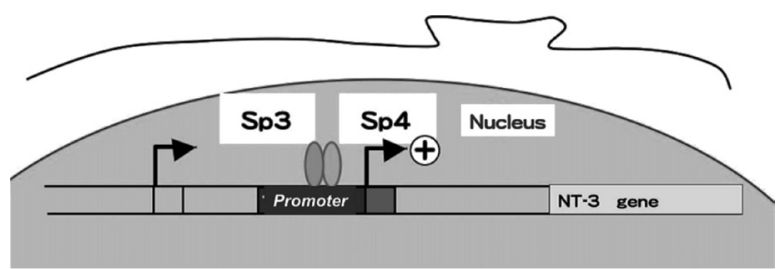

Fig. 9. Involvement of Sp3 and Sp4 in Neurotrophin-3 (NT-3) Gene Transcription

$\mathrm{Ca}^{2+}$ influx does not activate NT-3 gene transcription. During basal neuronal activity, $\mathrm{Sp} 3$ and $\mathrm{Sp} 4$ bind to GC-boxes to promote gene transcription.

consists of at least two untranslated exons IA (EIA) and IB (EIB), and a common exon II, which codes for the preproNT3 protein. ${ }^{30)}$ Promoters $\mathrm{A}$ and $\mathrm{B}$ are located upstream of EIA and EIB, respectively, resulting in expression of between two and six spliced variants in a variety of tissues. ${ }^{31)}$ We found an NT-3 transcript containing EIB that is predominantly expressed in cortical neurons, which preferentially utilize promoter $\mathrm{B}^{32)}$ Two tandemly repeated GC-boxes, located between -100 and -60 base pairs within promoter $\mathrm{B}$, are required for transcription of NT-3. Furthermore, we tried to investigate which transcription factors bind the NT-3 gene promoters and found that both specificity protein (Sp)3 and Sp4 bind to the Sp1 sequences within the GC boxes. Dominant negative Sp3 and Sp4 small interfering RNAs inhibited activation of NT-3 promoter B, suggesting that Sp3 and Sp4 contribute to NT-3 gene transcription (Fig. 9). Sp4 knock out mice display a reduction of NT-3 mRNA expression, supporting our study. ${ }^{33)}$ Unlike the BDNF gene, NT-3 gene expression is not up-regulated by $\mathrm{Ca}^{2+}$ entry via $\mathrm{L}-\mathrm{VDCC}$ and NMDA receptors. Conversely, NT-3 mRNA expression was down-regulated by membrane depolarization-induced $\mathrm{Ca}^{2+}$ entry in cerebellar granule cells. ${ }^{34)}$ Exclusive expression of the BDNF and NT-3 genes was also observed during cerebellar development. ${ }^{35)}$ However, these studies have not yet fully elucidated the signaling pathways or the transcription factors that are required for NT-3 promoter responsiveness to extracellular stimuli. Besides the NT-3 gene, a neuronal gene, p75 neurotrophin receptor, and the MeCP2 gene that is associated with Rett syndrome have also been identified as Sp1 familytarget genes. ${ }^{37,38)} \mathrm{Sp} 1, \mathrm{Sp} 3$ and $\mathrm{Sp} 4$ contain polyglutamine repeats and have been implicated in the pathogenesis of neurodegenerative diseases. ${ }^{39,40)}$ Therefore, the identification of Sp transcription factor target genes such as NT-3 would help elucidate the molecular events involved, not only in nervous system development, but also in neurodegenerative disorders.

\section{TRANSCRIPTION OF THE PACAP GENE}

Pituitary adenylate cyclase-activating polypeptide (PACAP) is a member of the vasoactive intestinal polypeptide/secretin/glucagon family. ${ }^{41,42)}$ The PACAP gene consists of six exons including the coding region, such that three transcripts can be produced by differential usage of alternative exons $1 \mathrm{~A}$ and $1 \mathrm{~B}$. In addition to the three previously reported transcripts, we found another novel PACAP transcript. ${ }^{43)}$ Like BDNF, PACAP gene transcription depends on neuronal activity that triggers $\mathrm{Ca}^{2+}$ influx into neurons. ${ }^{43}$ Thus, we investigated the $\mathrm{Ca}^{2+}$ responsive DNA elements and the transcription factors which bind to these responsive elements. PACAP 
transcripts containing exons $1 \mathrm{~A}$ or $1 \mathrm{~B}$ were increased by membrane depolarization. Therefore, we fused the promoter region including exon $1 \mathrm{~A}$ and $1 \mathrm{~B}$ to a firefly luciferase reporter vector. Analysis of reporter activation with several kinds of PACAP promoter mutants revealed a requirement for only one region, $\mathrm{CRE}$, in the transcriptional response to $\mathrm{KCl}$-induced membrane depolarization (Fig. 10). Activation of the PACAP promoter by $\mathrm{KCl}$ stimulation requires $\mathrm{Ca}^{2+}$ influx via both L-VDCC and NMDA receptors (Fig. 10). ${ }^{44)}$ The dependency of PACAP gene expression on $\mathrm{Ca}^{2+}$ signals is similar to that of the BDNF gene. However, PACAP, but not the BDNF gene, also responded to cAMP signals. Treatment with forskolin, a cAMP inducer, and $\mathrm{KCl}$ caused a synergistic increase in PACAP promoter activity and mRNA levels. Furthermore, the half life of PACAP mRNA was longer when cortical neurons were treated with forskolin or $\mathrm{KCl}$ and mRNA stabilization was synergistically induced by addition

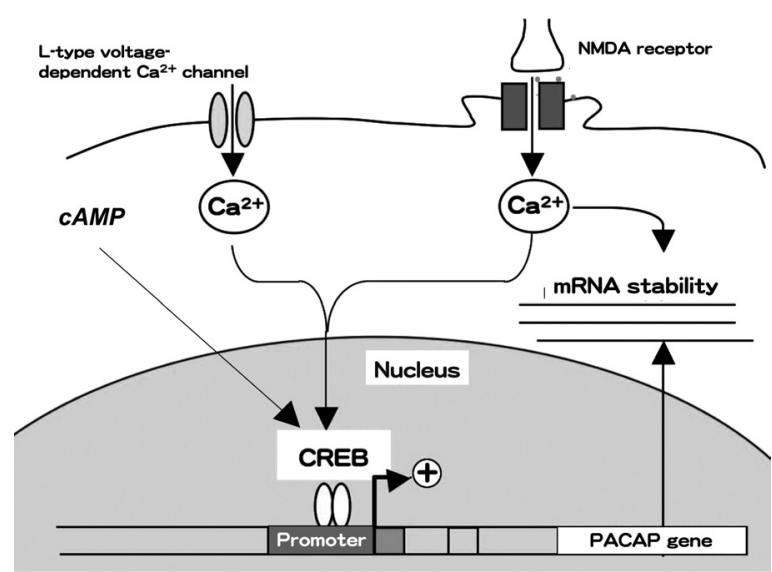

Fig. 10. PACAP Gene Transcription and mRNA Stabilization is Induced Not Only by $\mathrm{Ca}^{2+}$ But Also by cAMP Signals

The PACAP gene promoter is able to respond to $\mathrm{Ca}^{2+}$ entry via $\mathrm{L}-\mathrm{VDCC}$ and NMDA receptors. $\mathrm{Ca}^{2+}$ signaling pathways activate transcription factor CREB. Unlike BDNF gene, PACAP gene respond to cAMP signals. Convergence of $\mathrm{Ca}^{2+}$ with cAMP signals synergistically activates the PACAP gene promoter. Both promoter activity and mRNA stability are affected by $\mathrm{Ca}^{2+}$ and cAMP signals and eventually lead to accumulation of PACAP mRNA in neurons. of both forskolin and $\mathrm{KCl}$. Although such an activity-dependent mRNA stabilization has not been reported, the mechanism might be explained by the presence of $5^{\prime}$-AU rich elements, located in the $3^{\prime}$-untranslated region of mRNA. ${ }^{45}$ ) In this study, we demonstrated that the coordination of activity-dependent transcriptional activation and mRNA stabilization, which is mainly controlled by $\mathrm{Ca}^{2+}$ and cAMP signals, plays an important role in acutely changing the cellular content of specific mRNA species in response to glutamatergic and dopaminergic inputs, possibly leading to the formation of long-lasting synaptic plasticity.

Recent studies have demonstrated that the process of drug addiction seems to be related to the neuronal plasticity associated with natural reward-related learning and memory. ${ }^{46)}$ In this process, the integration of two neurotransmitters, glutamate and dopamine appears to play a key role in the induction of intracellular transcriptional and translational cascades leading to adaptive changes in gene expression. Dopamine receptor 1 is a G-protein-coupled receptor (GPCR) that facilitates an increase in intracellular cAMP levels. Therefore, we speculate that the accumulation PACAP mRNAs evoked by $\mathrm{Ca}^{2+}$ and cAMP signals might be regulated by activation of NMDA and dopamine receptors in vivo. Furthermore, PACAP or PACAP receptor KO mice display abnormal social behaviors as well as hyperactivity and impaired prepulse inhibition. ${ }^{4-50)}$ Taken together, these findings suggest an important role for PACAP in emotion and behavior. Thus, analysis of the transcriptional mechanisms that control expression of the PACAP gene may, in part, contribute to our understanding of the pathogenesis of psychological disorders.

\section{ACTIVITY-DEPENDENT NEURONAL SURVIVAL SUP- PORTED BY BDNF AND PACAP}

Membrane depolarization evoked by elevating $\mathrm{K}^{+}$concentrations is required for the survival of cerebellar granule cells (CGCs) and deprivation of membrane depolarization leads to apoptosis. This activity-dependent survival is mainly

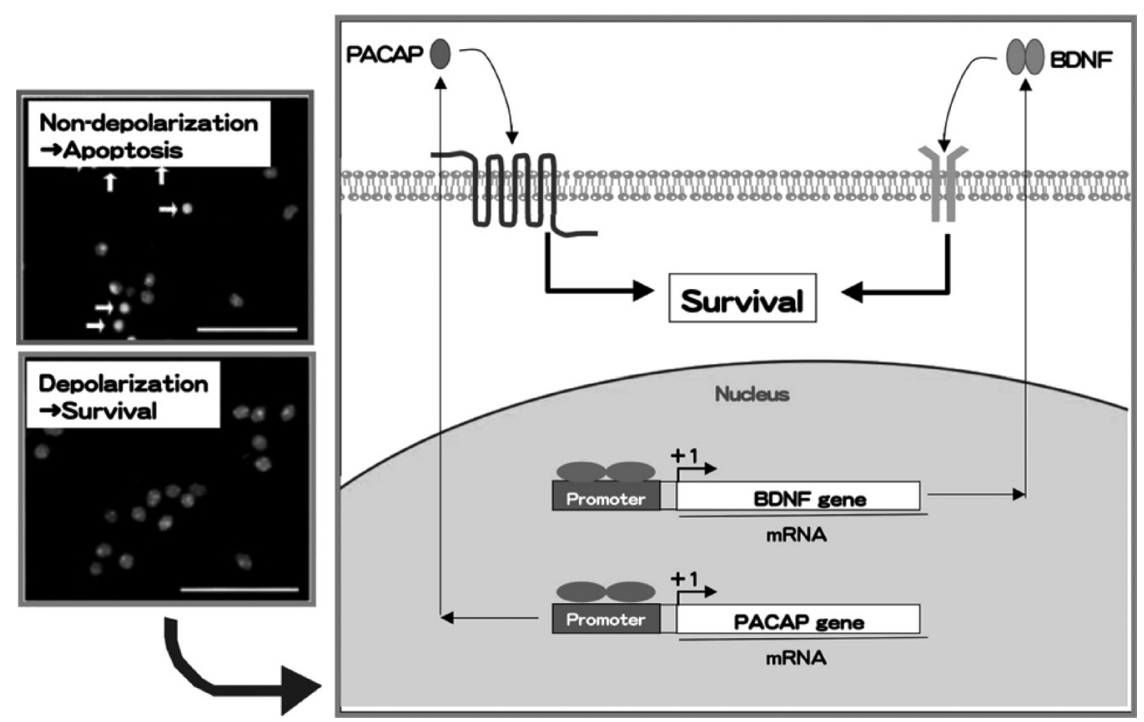

Fig. 11. Endogenous BDNF and PACAP Production Contribute to Activity-Dependent Neuronal Survival

The survival of cerebellar granule cells (CGCs) requires conditions that induce membrane depolarization $(25 \mathrm{~mm} \mathrm{KCl})$. This activity-dependent survival depends upon $\mathrm{Ca}^{2+}$ influx via L-VDCC. Under these conditions, the BDNF and PACAP genes are activated and involved in activity-dependent survival of CGCs. 


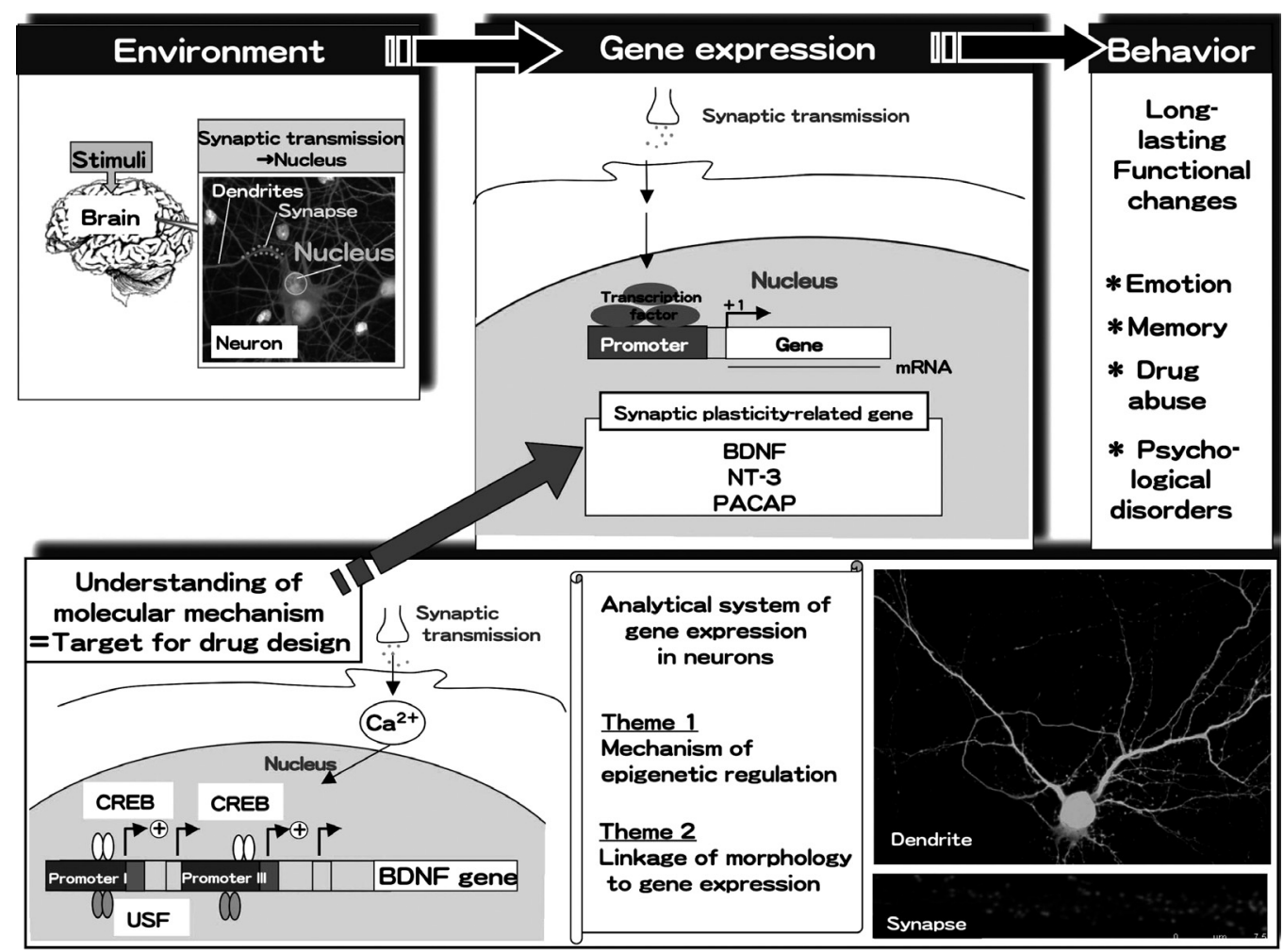

Fig. 12. Neuronal Gene Expression Is a Bridge between the Environment and Behavior

Reception of environmental stimuli triggers high frequency synaptic transmission in neurons and signals are transduced to the nucleus. Within the nucleus, activity-dependent $\mathrm{Ca}^{2+}$ signals activate gene expression of synaptic plasticity-regulated proteins. As a result of gene expression, long-lasting changes in neuronal function such as emotion, memory, drug abuse and psychological disorders occurs. Our understanding of the molecular mechanisms of synaptic plasticity-regulated gene expression may help in the search for novel drug targets for the treatment of neurological and psychological diseases. There are two themes for our future directions: one is an understanding of epigenetic gene regulation in neurons and the other is linking gene expression to neuronal morphology.

controlled by $\mathrm{Ca}^{2+}$ influx into CGCs through L-VDCC. ${ }^{51)}$ BDNF, secretogranin-II (Sg-II) and parathyroid hormone related peptide (PTHrP) genes are up-regulated by membrane depolarization in CGCs. ${ }^{52,53)}$ As described above, we found that expression of BDNF and PACAP genes is up-regulated by $\mathrm{Ca}^{2+}$ entry and signalling. Furthermore, it has been reported that endogenous BDNF expression contributes to activity-dependent survival of cortical neurons. ${ }^{54)}$ Therefore, we investigated whether PACAP is endogenously synthesized and whether it contributes to activity-dependent survival of CGCs in culture. The expression of PACAP mRNA was induced in CGCs and protein levels were up-regulated by elevating $\mathrm{KCl}$ concentrations. However, a specific PACAP receptor antagonist, PACAP(6-38), prevented the attenuation of apoptosis of CGCs, but only partially. ${ }^{55)}$ These observations support the view that a specific interaction of secreted PACAP with PACAP receptors, contributes to the activity-dependent survival of CGCs. The partial inhibitory effect of PACAP(6-38) on the attenuation of CGC apoptosis is probably due to the fact that membrane depolarization induces secretion of other proteins such as BDNF, PTHrP and VIP, which also enhance activity-dependent survival of CGCs. ${ }^{34,56)}$ These findings strongly indicate a physiological role for neuronal plasticity-related gene such as BDNF and PACAP in activity-dependent survival (Fig. 11).

\section{CONCLUSION AND FUTURE DIRECTIONS}

We focused on synaptic plasticity-related genes and eluci- dated several molecular mechanisms that underlie the regulation of neurotrophin genes by neuronal activity. We found that transcription factor CREB plays a crucial role in controlling BDNF and PACAP genes. However, it is still not clear how regulation of BDNF and PACAP gene expression is involved in the "long-lasting", functional changes in the brain.

Recently, maternal behavior toward offspring has been explained by epigenetic regulation or epigenetics and can affect "long-lasting" changes in the response of the offspring to stress throughout life. ${ }^{57,58)}$ "Epigenetics" refers to the selfperpetuating, post-translational modifications of DNA and nuclear proteins that produce "long-lasting" changes in gene expression as an indirect consequence, such as DNA (Cytosine-5) methylation, histone acetylation-deacetylation and histone methylation-demethylation. Epigenetic modulation of the genome is thought to be a necessary component for longterm memory, ${ }^{59,60)}$ therefore it would be worth trying to see if the BDNF gene is epigenetically regulated by DNA methyltransferases, histone acetyl transferases or by deacetylation during development, or in models of psychological disorders.

Another direction for future studies is how neuronal morphology is associated with gene expression. We are now focusing on actin-binding transcriptional coactivators and elucidating the mechanisms for its localization, transport from dendrites to the nucleus and transcriptional activation. ${ }^{61,62)}$

"Epigenetics" appears to be different from "neuronal morphology" in terms of gene expression. However, the two themes have a common feature that is, "trace" within the structure. We will aim to elucidate the molecular mecha- 
nisms of signal transduction from the synapse to the nucleus and vice versa. We believe that our future studies will provide new insights into drug design and diagnostic reagents (Fig. 12).

Acknowledgements I am grateful to Dr. Masaaki Tsuda for his encouragement and criticism. I thank Dr. Mamoru Fukuchi, all graduate and undergraduate students and everybody who got involved in this study. This study was supported in part by a Grant-in-Aid for Core Research for Evolutional Science and Technology (CREST) from the Science and Technology Corporation of Japan, by a Grant-in-Aid from the Ministry of Education, Culture, Sports, Science and Technology of Japan, by a Sasakawa Scientific Research Grant from the Japan Science Society, by the Hayashi Memorial Foundation for Female Natural Scientists, by Narishige Neuroscience Research Foundation, by the Tokyo Biochemical Research Foundation, by the Uehara Memorial Foundation and by the Takeda Science Foundation.

\section{REFERENCES}

1) West A. E., Chen W. G., Dalva M. B., Dolmetsch R. E., Kornhauser J. M., Shaywitz A. J., Takasu M. A., Tao X., Greenberg M. E., Proc. Natl. Acad. Sci. U.S.A., 98, 11024-11031 (2001).

2) Thoenen H., Science, 270, 475-489 (1995).

3) Ernfors P., Wetmore C., Olson L., Persson H., Neuron, 5, 511-526 (1990).

4) Ghosh A., Carnahan J., Greenberg M. E., Science, 263, 1618-1623 (1994).

5) Timmusk T., Palm K., Metsis M., Reintam T., Paalme V., Saarma M. Persson H., Neuron, 10, 475-489 (1993).

6) Tabuchi A., Sakaya H., Kisukeda T., Fushiki H., Tsuda M., J. Biol. Chem., 277, 35920-35931 (2002).

7) Xia Z., Dudek H., Miranti C. K., Greenberg M. E., J. Neurosci., 16, 5425-5436 (1996).

8) Tabuchi A., Nakaoka R., Amano K., Yukimine M., Andoh T., Kuraishi Y., Tsuda M., J. Biol. Chem., 275, 17269-17275 (2000).

9) Tao X., Finkbeiner S., Arnold D. B., Shaywitz A. J., Greenberg M. E., Neuron, 20, 709-726 (1998).

10) Shieh P. B., Hu S.-C., Bobb K., Timmusk T., Ghosh A., Neuron, 20, $727-740$ (1998)

11) Chen W. G., West A. E., Tao X., Corfas G., Szentirmay M. N., Sawadogo M., Vinson C., Greenberg M. E., J. Neurosci., 23, 25722581 (2003).

12) Tao X., West A. E., Chen W. G., Corfas G., Greenberg M. E., Neuron, 33, 383-395 (2002)

13) Mori N., Schoenherr C., Vanderbergh D. J., Anderson D. J., Neuron, 9, 45-54 (1992).

14) Kraner S. D., Chong J. A., Tsay H.-J., Mandel G., Neuron, 9, 37-44 (1992).

15) Timmusk T., Palm K., Lendahl U., Metsis M., J. Biol. Chem., 274, 1078-1084 (1999).

16) Tabuchi A., Nakatani C., Nakaoka R., Naruse Y., Kojima T., Mori N. Tsuda M., Biochem. Biophys. Res. Commun., 261, 233-237 (1999).

17) Chong J., Tapia-Ramirez J., Kim S., Toledo-Aral J. J., Zheng Y., Boutros M. C., Altshuller Y. M., Frohman M. A., Kraner S. D., Mandel G., Cell, 80, 949-957 (1995).

18) Schoenherr C., Anderson D. J., Science, 267, 1360-1363 (1995).

19) Tabuchi A., Yamada T., Sasagawa S., Naruse Y., Mori N., Tsuda M., Biochem. Biophys. Res. Commun., 290, 415-420 (2002).

20) Millecamps S., Kiefer H., Navarro V., Geoffroy M.-C., Robert J.-J., Finiels F., Mallet J., Barkats M., Nat. Biotechnol., 17, 865-869 (1999).

21) Klose R. J., Bord A. P., Trends Biochem. Sci., 31, 89-93 (2006)

22) Amir R. E., Van den Veyver I. B., Wan M., Tran C. Q., Francke U., Zoghbi H. Y., Nat. Genet., 23, 185-188 (1999).

23) Chen W. G., Chang Q., Lin Y., Meissner A., West A. E., Griffith E., Jaenisch R., Greenberg M. E., Science, 302, 885-889 (2003).

24) Zhou Z., Hong E. J., Cohen S., Zhao W., Ho H. H., Schmidt L., Chenm W. G., Lin Y., Savner E., Griffith E. C., Hu L., Steen J. A. J., Weitz C.
J., Greenberg M. E., Neuron, 52, 255-269 (2006).

25) Aid T., Kazantseva A., Piirsoo M., Palm K., Timmusk T., J. Neurosci Res., 85, 525-535 (2007).

26) Pruunsild P., Kazantseva A., Aid T., Palm K., Timmusk T., Genomics, 90, 397-406 (2007).

27) McAllister A. K., Katz L. C., Lo D. C., Annu. Rev. Neurosci., 22, 295-318 (1999).

28) Ku B., Prog. Brain Res., 146, 137-150 (2004)

29) Zweifel L. S., Kuruvilla R., Ginty D. D., Nat. Rev. Neurosci., 6, 615625 (2005)

30) Leingartner A., Lindholm D., Eur. J. Neurosci., 6, 1149-1159 (1994).

31) Kendall S., Yeo M., Henttu P., Tomlinson D. R., J. Neurochem., 75, $41-47$ (2000).

32) Ishimaru N., Tabuchi A., Hara D., Hayashi H., Sugimoto T., Yasuhara M., Shiota J., Tsuda M., J. Neurochem., 100, 520-531 (2007).

33) Zhou X., Long J. M., Geyer M. A., Masliah E., Kelsoe J. R., Wynshaw-Boris A., Chien K. R., Mol. Psychiatry, 10, $393-406$ (2005).

34) Ichikawa D., Tabuchi A., Taoka A., Tsuchiya T., Tsuda M., Brain Res. Mol. Brain Res., 56, 218-226 (1998).

35) Segal R. A., Takahashi H., Mckay D. G., Neuron, 9, 1043-1052 (1992).

36) Zhou X., Long J. M., Geyer M. A., Masliah E., Kelsoe J. R., Wynshaw-Boris A., Shien K. R., Mol. Psychiatry, 10, 393-406 (2005).

37) Poukka H., Kallio P. J., Janne O. A., Palvino J. J., Biochem. Biophys. Res. Commun., 229, 565-570 (1996).

38) Marin M., Karis A., Visser P., Grosveld F., Philipsen S., Cell, 89 $619-628$ (1997).

39) Suske G., Gene, 238, 291-300 (1999)

40) Li S.-H., Cheng A. L., Zhou H., Lam S., Rao M., Li H., Li X.-J., Mol. Cell. Biol., 22, 1277-1287 (2002).

41) Miyata A., Arimura A., Dahl R. R., Minamino N., Uehara A., Jiang L., Culler M. D., Coy D. H., Biochem. Biophys. Res. Commun., 164 567-574 (1989)

42) Vaudry D., Gonzalez B. J., Bassile M., Yon L., Fournier A., Vaudry H., Pharmacol. Rev., 52, 269-324 (2000).

43) Tabuchi A., Koizumi M., Tsuda M., NeuroReport, 12, 1181-1186 (2001).

44) Fukuchi M., Tabuchi A., Tsuda M., J. Biol. Chem., 279, 4785647865 (2004)

45) Shaw G., Kamen R., Cell, 46, 659-667 (1986).

46) Kelly A. E., Neuron, 44, 151-179 (2004)

47) Hashimoto H., Shigemoto R., Mori K., Takahashi K., Nagata S., Neuron, 8, 811-819 (1992).

48) Hashimoto H., Shintani N., Tanaka K., Mori W., Hirose M., Matsuda T., Sakaue M., Miyazaki J., Niwa H., Tashiro F., Yamamoto K., Koga K., Tomimoto S., Kunugi A., Suetake S., Baba A., Proc. Natl. Acad. Sci. U.S.A., 98, 13355-13360 (2001).

49) Nicot A., Otto T., Brabet P., Dicicco-Bloom E. M., J. Neurosci., 24 8786 -8795 (2004)

50) Tanaka K., Shintani N., Hashimoto H., Kawagishi N., Ago Y., Matsuda T., Hashimoto R., Kunugi H., Yamamoto A., Kawaguchi C., Shimada T., Baba A., J. Neurosci., 10, 5091-5097 (2006).

51) Gallo V., Kingsbury A., Balaqzs R., Jorgensen O. S., J. Neurosci., 7, 2203-2213 (1987).

52) Fujita Y., Katagi J., Tabuchi A., Tsuchiya T., Tsuda M., Brain Res. Mol. Brain Res., 63, 316-324 (1999).

53) Ono T., Inokuchi K., Ogura A., Ikawa Y., Kudo Y., Kawashima S., J. Biol. Chem., 272, 14404-14411 (1997).

54) Ghosh A., Carnahan J., Greenberg M. E., Science, 263, 1618-1623 (1994).

55) Tabuchi A., Koizumi M., Nakatsubo J., Yaguchi T., Tsuda M., Neurosci. Res., 39, 85-93 (2001).

56) Fukuchi M., Sakuragawa S., Tabuchi A., Tsuda M., J. Neurosci. Res., 77, 26-34 (2004)

57) Weaver J. C. G., Cervoni N., Champagne F. A., D’Alessio A. C. Sharma S., Seckl J. R., Dymov S., Szyf M., Meaney M. J., Nat. Neurosci., 7, 847-854 (2004).

58) Meaney M. J., Szyf M., Trends Neurosci., 28, 456-463 (2005).

59) Levenson J. M., O’Riordan K. J., Brown K. D., Trinh M. A., Molfese D. L., Sweatt J. D., J. Biol. Chem., 279, 40545-40559 (2004).

60) Levenson J. M., Roth T. L., Lubin F. D., Miller C. A., Huang I., Desai P., Malone L. M., Sweatt J. D., J. Biol. Chem., 281, 15763-15773 (2006).

61) Tabuchi A., Estevez M., Henderson, J. A., Marx R., Shiota J. Nakano H., Baraban J. M., J. Neurochem., 94, 169-180 (2005).

62) Shiota J., Ishikawa M., Sakagami H., Tsuda M., Baraban J. M., Tabuchi A., J. Neurochem., 98, 1778-1788 (2006). 